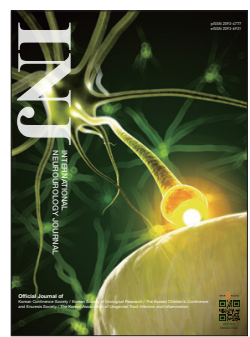

\title{
Inflammation as the Potential Basis in Depression
}

\author{
Sung Ho Maeng ${ }^{1}$, Heeok Hong ${ }^{2}$ \\ ${ }^{1}$ Department of Gerontology, Kyung Hee University Graduate School of East-West Medical Science, Yongin, Korea \\ ${ }^{2}$ Department of Animal Science and Technology, Konkuk University, Seoul, Korea
}

\begin{abstract}
There is growing evidence of the association between inflammation and stress-related disorders including depression. The positive correlation between the increased levels of inflammatory cytokines observed in patients with other diseases and the byproduct of the depressive symptoms may be caused by chronic stress. Increased neuroinflammatory responses are capable of activating microglia and astrocytes, which leads to release pro-inflammatory cytokines. Moreover, elevated levels of inflammatory cytokines such as tumor necrosis factor-alpha, interleukin (IL)-1, and IL-6 are causally related to various aspects of depression such as the behavioral symptomatology. Eventually, these elevated cytokines aggravate and propagate neuroinflammation, impairing brain functions. Thus, activated astrocytes and microglia may be potential mediators in neuroinflammatory processes contributing to the development of depression.
\end{abstract}

Keywords: Inflammation; Depression; Inflammatory cytokines; Microglia; Astrocytes

- Conflict of Interest: No potential conflict of interest relevant to this article was reported.

\section{INTRODUCTION}

Inflammation can be defined as one of the immune responses for protecting living organisms from damage or microbial infection [1]. Immune system can be triggered by various factors such as pathogens, damage cells and stress that may induce acute or chronic inflammatory responses in organs including brain, potentially leading to tissue damage or disease [1,2]. Many diseases and conditions have induced to higher levels of inflammatory cytokines which related to depression risk [3]. For example, there are cancer $[4,5]$, chronic alcohol abuse [6,7], psychosocial stress $[8,9]$, and dermatitis $[10,11]$.

The variety of factors activate inflammatory cells and trigger inflammatory signaling pathways including nuclear factor kappa B (NF- $\mathrm{KB}$ ) and mitogen-activated protein kinase (MAPK) pathways [12].
NF- $\kappa \mathrm{B}$, a transcription factor, is activated by IкB phosphorylation induced by IKB kinase (IKK) to promote the production and distribution of inflammatory cytokines such as tumor necrosis factor-alpha (TNF- $\alpha$ ), interleukin (IL)-1 $\beta$, and IL-6 [13]. MAPK is activated by cytokines. The mammalian MAPKs include extracellular-signal-regulated kinase ERK1/2, p38, and cJun N-terminal kinases (JNK) [14]. Furthermore, JNK and p38 are responsive to stress and cytokines [15]. Activations of MAPKs lead to phosphorylation and activation of transcription factors, too. Signaling through transcription factors results in release of inflammatory cytokines including IL-1 $\beta$, IL-6, and TNF- $\alpha$.

Moreover, inflammatory intermediates including prostaglandin E2 and nitric oxide are produced by cyclooxygenase 2 and inducible nitric oxide synthase, which react to inflammatory cytokine [16,17]. Excess activation of these enzymes leads to re-

Corresponding author: Heeok Hong (iD https://orcid.org/0000-0001-6315-7097

Department of Animal Science and Technology, Konkuk University, 120 Neungdong-ro, Gwangjin-gu, Seoul 05029, Korea

E-mail: hhong58@konkuk.ac.kr / Tel:+82-2-2049-6274 / Fax: +82-2-455-1044

Submitted: November 21, 2019 / Accepted after revision: November 25, 2019 
lease of inflammatory cytokines. Therefore, inflammatory cytokines, enzymes, and transcription factors can be used as biomarkers in the inflammatory response.

The brain has been known as an organ with little inflammatory response because it has a special structure that is inaccessible to external bacteria or foreign substances, but it is known that neuroglial cells in the brain control the inflammatory/immune reaction and that an abnormality in these cells function causes brain disease including depression [18,19].

Inflammation of the brain is caused by microglia activation and the release of cytokines, chemokines, and pro-inflammatory factors [20].

Several papers suggested that inflammation was related to depression. Cytokines can be produced by neurons, astrocytes and microglia within the brain [21]. Frick et al. [22] have proposed that these cells may be potential mediators of inflammatory alterations in depression.

Glial cells are essential players in central nervous system (CNS) development, maintenance, and decline [23]. It is known that mild activation of microglia and astrocytes usually indicates neuroprotection and improves the early symptoms of neurodegeneration, while strong activation of them leads to overproduction of cytokines, which promotes neurodegeneration [24]. Hong et al. [25] have reported that activation of the peripheral immune system leads to elevated cytokines that are actively transported into the CNS and stimulate microglia and astrocytes.

Astrocytes have powerful pro-inflammatory potential in the neuroinflammatory response [26].

Neuroinflammation is defined as the reactive state of astrocytes and microglia induced by pathological conditions [26]. Reactive astrocytes and microglia are known to mediate the innate immune responses in the brain [27]. Astrocytes respond to CNS injury and disease through a process called reactive astrogliosis, an activated state of glia cells that contributes to inflammation [26,28-30]. These cells produce and secrete pro-inflammatory cytokines, leading to neuroinflammation and contributing to the development of depression.

According to several clinical studies, patients with major depression showed elevated levels of TNF- $\alpha$, IL-1 $\beta$, and IL- 6 , but low level of IL-8 compared to healthy controls $[9,31]$. Several postmortem studies demonstrated the presence of inflammatory markers in the brains of depressed patients. Tonelli et al. [32] reported that female suicide victims had increased levels of IL-4 and male suicide victims showed elevated levels of IL-13 com- pared to controls. Moreover, 24 teenager suicide victims had higher TNF- $\alpha$, IL-1 $\beta$, and IL- 6 than normal control subjects in Brodmann area 10 [33], a brain region previously associated with suicidal ideation [34].

On the other hand, Wang et al. [35] did not observe changes in levels of TNF- $\alpha$ and IL-1 $\beta$ in depressed patients compared to controls. Clark et al. [36] found that the mRNA levels of TNF- $\alpha$ were lower in the ventrolateral prefrontal cortex (PFC) of depressed individuals than in nonpsychiatric controls.

It would be difficult to conclude that all cases of depression are associated with increased inflammation, not only because most people with elevated inflammation do not develop depression, but also the results of human and animal studies have not been inconsistent.

In this review, we summarized and discuss briefly the potential roles of transcription factor and pro-inflammatory cytokines in depression.

\section{ACTIVATION OF NF- $\kappa B$ PATHWAY}

The variety of factors activate inflammatory cells and trigger inflammatory signaling pathways [12]. NF- $\kappa B$ pathway, one of major inflammatory pathways, plays major roles in inflammation, and dysregulation of this pathway may lead to production of inflammatory cytokines-associated depression $[1,12]$.

The transcription factor NF- $\mathrm{kB}$ plays important roles in innate and adaptive immune responses and serves as a pivotal mediator of inflammatory responses [13].

The NF- $\mathrm{BB}$ pathway acts as a general stress sensor operated by a number of adverse conditions, such as inflammation [37]. Inflammation activates adaptive responses that are controlled by NF- $\mathrm{kB}$ signaling pathway and these systems can be triggered by various factors including cytokines and toll-like receptor (TLR) ligands [37].

TLRs activates IKK in the cytoplasm and IKK phosphory-

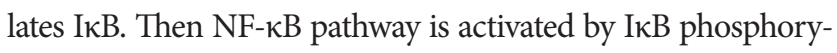
lation. The activated NF- $\mathrm{kB}$ moves into nucleus to activate gene transcription of inflammatory cytokines [1]. Thus, NF- $\mathrm{kB}$ regulates the expression of pro-inflammatory cytokines.

It is known that NF- $\mathrm{kB}$ is strongly related to neuroinflammation in astrocytes and microglia because NF- $\kappa \mathrm{B}$ regulates the neuronal inflammatory reactions around the neuronal environment $[38,39]$. Moreover, traditionally activated neuroinflammatory microglia have strong NF-kB pathway activation that is required for the activation of neuroinflammatory reactive as- 
trocytes [29]. NF- $\kappa B$ transcription factors are abundant in neurons, glial cells and cerebral blood vessels. Therefore, depression is associated with NF- $\mathrm{kB}$ activated by inflammatory mediators. $\mathrm{Xu}$ et al. [40] found that NF- $\mathrm{KB}$ activation was linked to depression in chronic inflammatory patients. Adolescents with depression had higher levels of activated NF- $\kappa B$ in monocytes than controls and these levels were strongly associated with the severity of depressive symptoms [41].

In animal models, chronic unpredictable stress-induced overexpression of NF- $\mathrm{kB}$ in the frontal cortex and hippocampus and depressive-like behavior [42]. The antidepressant treatment inhibited the expression of NF- $\mathrm{kB}$ in chronic unpredictable mild stress-induced depressive mice [43]. Although hyperactivity of NF- $\kappa B$ has been associated with stress and depression, a postmortem study showed that NF- $\mathrm{kB}$ expression was decreased in patients with depression compared with controls [44] and NF- $\mathrm{kB}$ mRNA and protein expression reduced slightly in chronic stress-induced depressed rats [45].

As noted above, the results of studies were inconsistent. Nevertheless, it is considered that the role of NF- $\mathrm{kB}$ is important in the regulation of neuroinflammation-associated disease pathogenesis through the control of inflammatory mediators and the transcription and expression of inflammatory cytokines in brain.

Therefore, a better understanding of the mechanism that underlies NF- $\kappa \mathrm{B}$ activation and pro-inflammatory function is of great significance for therapeutic strategies in the treatment of neuroinflammation.

\section{PRO-INFLAMMATORY CYTOKINES}

Several studies demonstrated that inflammatory cytokines affect the brain directly or indirectly, increasing the depression risk [3,46-50].

Cytokines belong to the broad and loose category of important proteins in cell signaling. These include chemokines, interferons (IFNs), IL, and TNFs. It is known that cytokines are produced by immune cells and microglia and astrocytes in brain [21,51].

The production of IL1, IL-6, or TNF- $\alpha$ in the innate immune system results in the activation of the so-called Thelper 17 cells which produce cytokines like IL-17, IL-21, and IL-22 [52]. Therefore, they are called pro-inflammatory cytokines together with IL-1, IL-6, TNF- $\alpha$ and IL-17, IL-21, and IL-22, which are cytokines that promote inflammation [21]. These pro-inflam- matory cytokines may lead to the development of depression through brain structural changes and brain dysfunction.

According to meta-analytic studies, depression patients have elevated IL-6, TNF- $\alpha$, and IL-1 level compared to healthy people $[53,54]$. Similarly, production of IL-6, IL-10, and TNF- $\alpha$ levels have been shown to be increased in animal models for depression using acute or restraint stress [55].

Studies showed that increased levels of cytokines including IL- $1 \beta$, IL- 6 , and TNF- $\alpha$ have been closely related with the pathogenesis of depression. Furthermore, pro-inflammatory cytokines are considered suitable as a biomarker of depression. Thus, we reviewed the association between the incidence of depression and pro-inflammatory cytokines such as TNF- $\alpha$, IL-1, and IL-6.

\section{TNF- $a$}

TNF- $\alpha$ is one of the more important pro-inflammatory cytokines in depression, playing a central role in both initiation and regulation of the cytokine cascade during a response to the neuroinflammation [56]. TNF- $\alpha$ exerts its biological functions by binding to tumor necrosis factor receptor 1 (TNFR1) and 2 (TNFR2) and in the brain, TNFR1 appears to show a constructive pattern of expression, while TNFR2 is mainly expressed in stimulatory conditions [57].

TNF- $\alpha$ may be based on the mechanism of depression by an upregulation of the hypothalamic-pituitary-adrenocortical (HPA) axis [9]. Moreover, the uptake of serotonin is diminished and tryptophan deletion during the process of depression because TNF- $\alpha$ can regulate neuronal serotonin transporter and indoleamine 2,3-dioxygenase activities [57].

In depression patients, Schmidt et al. [54] found significantly higher TNF- $\alpha$ level compared to healthy people. Recently, Köhler et al. [58] found that patients with major depressive disorder (MDD) had elevated peripheral level of TNF- $\alpha$ compared to healthy controls in meta-analysis of 82 studies. Moreover, they observed that in a meta-analysis of 45 antidepressant treatment studies peripheral levels of TNF- $\alpha$ decreased in response to therapy [53]. Muthuramalingam et al. [59] found that depressive patients showed significantly raised TNF- $\alpha$ level compared to healthy people and TNF- $\alpha$ level of female patients tended to be higher than that of male patients. Himmerich et al. [55] found that TNF- $\alpha$ levels of rats that underwent acute or chronic stress were higher compared to those of nonstressed rats then they proposed alteration of TNF- $\alpha$ level might indicate a pathophysiological pathway from acute and chronic 
stress to the development of depression.

In systemic lupus erythematosus patient with depressive symptoms, a positive correlation between the severity of depressive symptoms and serum TNF- $\alpha$ levels was observed, while serum TNF- $\alpha$ levels were independently associated with depressive symptoms in the multivariate analysis [57]. Additionally, a meta-analysis of 22 antidepressant treatment studies found that TNF- $\alpha$ level in depressive patients did not decrease in response to therapy [60]. Whereas Miklowitz et al. [41] found that TNF- $a$ level in adolescents with depression did not differ from healthy controls.

As mentioned above, the psychological stress that can affect the development of depression, even though this pro-inflammatory cytokine has not been shown to have been elevated by all studies of patients with depression, results in an increase in pro-inflammatory cytokine levels and affects gene transcription by pro-inflammatory cytokines.

Taken together, although the TNF- $\alpha$ level is still debatable for its association with the depression, it has been able to confirm that there is the presence of immunological basis for depression.

\section{Interleukin $1 \beta$}

The microglia activation and the expression of inflammatory cytokine IL-1 in CNS have been considered almost identical to neuroinflammation that induce structure changes at the synaptic level [61].

IL-1 $\beta$ has been known as a master regulator of inflammatory reactions within the brain inflammatory cascade because of its essential role in regulating the expression of other pro-inflammatory cytokines, including TNF- $\alpha$ and IL- 6 , thus this IL is able to control the onset of neuroinflammation [21,61]. IL-1 $\beta$ produced by macrophages, endothelial cells, and astrocytes has been found to be an important risk factor for the developing symptoms of depression [21].

Recent studies have suggested that depression is associated with high levels of several inflammatory cytokines such as IL$1 \beta$, IL- 6 , and TNF- $\alpha$.

There are various pathways in which cytokines may affect pathophysiology of depression. Cytokine directly stimulates the HPA axis and chronic hyperactivity of the HPA axis leads to excessive secretion of cortisol, which eventually affects the nervous, endocrine, and immune systems $[9,62,63]$. The HPA axis response is one of many body systems designed to assist organisms respond to adversity [64]. IL-1 $\beta$ may influence the pathophysiology of depression through various pathways. It has been reported that the HPA axis function is upregulated by pro-inflammatory cytokines, particularly IL-1 $\beta$ [65].

Keller et al. [63] investigated that patients with depression disproportionately showed chronic hyperactivity of the HPA axis and had higher cortisol than those of healthy controls.

IL- $1 \beta$ intersects the blood-brain barrier and then alters the HPA axis. IL-1 $\beta$ reduces the re-uptake of serotonin from the synaptic cleft resulting in depressive symptoms. Moreover, IL-1 $\beta$ plays a role in the hypersecretions of adrenocorticotropic hormone (ACTH) and cortisol [65].

Sahay and Hen [66] observed that hippocampus volume of depressed patients was reduced in associated with disorder duration. In the mouse model of IFN- $\gamma$-induced depression, hippocampal IL-1 $\beta$ expression was induced depressive behavior [67]. These changes were not observed in IL-1 receptor knockout mice [65]. Therefore, elevated levels of IL-1 $\beta$ can lead to the development of depression.

Elevated levels of IL-1 and IL-6 have served as consistent biomarkers of depression according to several studies. Ng et al. [20] reported that elderly with depression were significantly higher in their peripheral IL- $1 \beta$ levels than control participants in meta-analysis. They also found that after Bonferroni adjustment, only peripheral levels of IL-1 $\beta$ remained significantly higher in elderly with depression than controls.

Zou et al. [9] found linear correlation between IL-1 $\beta$ and severity of depression and higher IL- $1 \beta$ level was associated with higher Hamilton Depression Rating Scale scores. A meta-analysis study found that the blood levels of IL- $1 \beta$ were significantly increased in suicidal patients with depression compared to nonsuicidal patients with depression. Furthermore, in postmortem brain of suicide victims, levels of IL- $1 \beta$ were significantly increased compared with those of healthy controls [68].

Pandey et al. [33,69] reported that the mRNA and protein expression levels of IL-1 $\beta$ in the PFC were significantly increased in 24 teenage suicide victims and in 24 depressed individuals who died by suicide compared with normal control subjects, respectively.

Correlations of IL- $1 \beta$ and the development of depression have been widely reported as mentioned above, although there are also some reports that fail to show correlation between IL$1 \beta$ level and the pathophysiology of depression.

The cohort study has shown that the levels of mRNA and protein expression of IL-1 in recurrent depressed patients tend to be slightly higher than those of patients with the first episode of depression, but there was no significant difference [54]. Tor- 
res-Platas et al. [70] observed that IL-1 $\beta$ expression of depressed suicides was similar to those of sudden-death controls in the dorsal anterior cingulate cortex white matter. This region is known to control cognition, motor, and emotion [16]. Ovaskainen et al. [71] reported that in the males and females with depressive symptomatology, IL- $1 \beta$ concentrations were not significantly changed as compared with the nondepressed males and females, respectively.

Taken together, it is possible that increased levels of IL-1 $\beta$, pro-inflammatory cytokines, may contribute to the pathophysiology of depression inducing the HPA axis hyperactivity, neuroendocrine changes, neurotransmitters, neurodegeneration, or indeed other yet unknown mechanism.

\section{Interleukin 6}

IL-6 is an important and multifunctional cytokine within the immune system that contributes as an inflammatory and antiinflammatory [72].

It is known that the cytokine IL-6 has been linked to stressrelated disorders such as depression [73]. Maydych [8] suggested that psychological stress that has an effect on inflammatory cytokines also can affect the onset, maintenance, and recurrence of depression.

IL-6 induces increased production of metabolites by astrocytes under stress [74]. It is known that microglia and astrocytes modulate inflammation in the CNS [28].

Microglia is known to regulate pro-inflammatory responses in astrocytes, but it is yet unclear about its mechanism [29,75]. IL- 6 can be produced by activated microglial cells and astrocytes in the brain [21].

Abnormality of IL-6 has been implicated in the pathophysiology of MDD, based on both human and animal studies. Many studies in recent have supported the biological correlation between depression and inflammation [20,48,55,73,76,77]. In particular, the increase in IL-6 level was significantly elevated in depression compared with control according to meta-analysis study $[20,48,77]$ and IFN- $\alpha$ therapy in patients with chronic hepatitis $\mathrm{C}$ showed to often (frequently) develop depression [78].

Moreover, level of IL-6 was increased in animal with depression induced by using acute or restraint stress [55]. In animal studies, IL-6 levels in cerebrospinal fluid were elevated by maternal deprivation [79] and repeated social defeat stress-induced increased IL-6 mRNA expression of microglia [80].

Goldsmith et al. [81] found that patient with depression showed elevated levels of IL-6 compared to healthy controls but significantly decreased following treatment in MDD. In postmortem studies, Il-6 levels were significantly elevated compared to those of healthy controls [69]. Across 24 studies of MDD showed that increased IL-6 levels were associated with MDD [48].

A number of researchers have suggested a functional role for IL-6 in the development of depression and a potential for targeting it to treat depression in humans [82-84].

Khandaker et al. [82] provided the first evidence about the relationship between the peripheral inflammation and the occurrence of depression, which children with high IL-6 serum levels at age 9 were 10\% greater risk of developing depression by age 18 than the healthy people or children with low levels of IL-6 in a longitudinal study. Moreover, Ng et al. [20] proposed that peripheral pro-inflammatory marker IL-6 is likely to be increased in depression.

Even several studies observed abnormal levels of pro-inflammatory cytokines in depressive and suicidal patients [48,70,85], it is not clear if similar abnormalities of cytokines are present in the brain of depressive and suicidal patients. Zou et al. [9] found that IL-6 levels in 117 depressed patients were slightly higher than those in the 102 healthy standard group, but there were no significant differences. Cohort study showed that mRNA and protein expression of IL-6 in patients with recurrent depression were similar to those of patients with the first episode of depression [86]. Walker et al. [87] reported that antidepressant treatment did not lead to change the plasma levels of IL-6 in rat treated with ACTH.

Despite numerous studies showing a correlation between depression and inflammation, it is still unclear whether inflammation trigger depression or inflammation is simply caused by depression.

As such, at the current state of investigation, being difficult enough to firmly place a causative relation for depression as a neuroinflammatory expression, it would be even more difficult to associate voiding in an associated symptom in these patients $[25,88]$. While there seems to be a significant clinical presence of voiding dysfunction in depression, and a tentative suggestion between voiding dysfunction and neuroinflammation, the difficult task of associating between all 3 states have yet to be studied.

Nevertheless, there is growing proposals that IL- 6 levels may serve as a predictive biomarker to resolve negative moods in people suffering from mental and social stress, thus IL-6 levels are believed to be associated with the incidence of depression. 


\section{CONCLUSION}

As mentioned above, cytokines are produced by microglia and astrocytes in the brain and peripherally produced cytokines access the brain through leaky sections of the blood-brain barrier. However, it is not currently clear about the mechanism by which these peripheral inflammatory responses signal the brain. Nevertheless, multiple studies have shown hyper-activation of the neuroinmmune system is strongly linked to the development of neuropsychiatric disorders and the potential role of inflammatory cytokines related to neuroinflammation. Neuroinflammation may be a key element in the pathological progression of depression.

A better understanding of the inflammatory response pathways and molecular mechanisms in brain will undoubtedly contribute to the improved prevention and treatment of depressive disorder, and more studies are needed to do so.

\section{AUTHOR CONTRIBUTION STATEMENT}

- Full access to all the data in the study and takes responsibility for the integrity of the data and the accuracy of the data analysis: $H H, S H M$

- Study concept and design: $H H$

- Acquisition of data: $H H, S H M$

- Analysis and interpretation of data: $H H, S H M$

- Drafting of the manuscript: $\mathrm{HH}$

- Critical revision of the manuscript for important intellectual content: $\mathrm{HH}$

- Administrative, technical, or material support: $H H$, SHM

-Study supervision: $\mathrm{HH}$

\section{REFERENCES}

1. Chen L, Deng H, Cui H, Fang J, Zuo Z, Deng J, et al. Inflammatory responses and inflammation-associated diseases in organs. Oncotarget 2017;9:7204-18.

2. Prame Kumar K, Nicholls AJ, Wong CHY. Partners in crime: neutrophils and monocytes/macrophages in inflammation and disease. Cell Tissue Res 2018;371:551-65.

3. Lotrich FE. Inflammatory cytokine-associated depression. Brain Res 2015;1617:113-25.

4. Miranda DO, Anatriello E, Azevedo LR, Cordeiro JFC, Peria FM, Flória-Santos M, et al. Elevated serum levels of proinflammatory cytokines potentially correlate with depression and anxiety in colorectal cancer patients in different stages of the antitumor therapy. Cytokine 2018;104:72-7.

5. Li M, Kouzmina E, McCusker M, Rodin D, Boutros PC, Paige CJ, et al. Cytokines and depression in cancer patients and caregivers. Neuropsychiatr Dis Treat 2017;13:2903-11.

6. Kalejaiye O, Getachew B, Ferguson CL, Taylor RE, Tizabi Y. Alcohol-induced increases in inflammatory cytokines are attenuated by nicotine in region-selective manner in male rats. J Drug Alcohol Res 2017;6 [Epub]. pii: 236036. https://doi.org/10.4303/jdar/236036.

7. Martinez P, Lien L, Zemore S, Bramness JG, Neupane SP. Circulating cytokine levels are associated with symptoms of depression and anxiety among people with alcohol and drug use disorders. J Neuroimmunol 2018;318:80-6.

8. Maydych V. The interplay between stress, inflammation, and emotional attention: relevance for depression. Front Neurosci 2019;13: 384.

9. Zou W, Feng R, Yang Y. Changes in the serum levels of inflammatory cytokines in antidepressant drug-naive patients with major depression. PLoS One 2018;13:e0197267.

10. Tohid H, Aleem D, Jackson C. Major depression and psoriasis: a psychodermatological phenomenon. Skin Pharmacol Physiol 2016; 29:220-30.

11. Farzanfar D, Dowlati Y, French LE, Lowes MA, Alavi A. Inflammation: a contributor to depressive comorbidity in inflammatory skin disease. Skin Pharmacol Physiol 2018;31:246-51.

12. Dong J, Qu Y, Li J, Cui L, Wang Y, Lin J, et al. Cortisol inhibits NF$\kappa B$ and MAPK pathways in LPS activated bovine endometrial epithelial cells. Int Immunopharmacol 2018;56:71-7.

13. Liu T, Zhang L, Joo D, Sun SC. NF-kB signaling in inflammation. Signal Transduct Target Ther 2017;2 [Epub]. pii: 17023. https://doi. org/10.1038/sigtrans.2017.23.

14. Kim EK, Choi EJ. Pathological roles of MAPK signaling pathways in human diseases. Biochim Biophys Acta 2010;1802:396-405.

15. Sabio G, Davis RJ. TNF and MAP kinase signalling pathways. Semin Immunol 2014;26:237-45.

16. Kang CH, Choi YH, Choi IW, Lee JD, Kim GY. Inhibition of lipopolysaccharide-induced iNOS, COX-2, and TNF- $\alpha$ expression by aqueous extract of Orixa Japonica in RAW 264.7 cells via suppression of NF-kB activity. Trop J Pharm Res 2011;10:161-8.

17. Guerri $C$, Pascual M. Impact of neuroimmune activation induced by alcohol or drug abuse on adolescent brain development. Int J Dev Neurosci 2019;77:89-98.

18. Chen WW, Zhang X, Huang WJ. Role of neuroinflammation in neurodegenerative diseases (Review). Mol Med Rep 2016;13:33916. 
19. Russo MV, McGavern DB. Immune surveillance of the CNS following infection and injury. Trends Immunol 2015;36:637-50.

20. Ng A, Tam WW, Zhang MW, Ho CS, Husain SF, McIntyre RS, et al. IL-1 $\beta$, IL-6, TNF- $\alpha$ and CRP in elderly patients with depression or Alzheimer's disease: systematic review and meta-analysis. Sci Rep 2018;8:12050.

21. Himmerich H, Patsalos O, Lichtblau N, Ibrahim MAA, Dalton B. Cytokine research in depression: principles, challenges, and open questions. Front Psychiatry 2019;10:30.

22. Frick LR, Williams K, Pittenger C. Microglial dysregulation in psychiatric disease. Clin Dev Immunol 2013;2013:608654.

23. Guttenplan KA, Liddelow SA. Astrocytes and microglia: models and tools. J Exp Med 2019;216:71-83.

24. Sochocka M, Diniz BS, Leszek J. Inflammatory response in the CNS: friend or foe? Mol Neurobiol 2017;54:8071-89.

25. Hong H, Kim BS, Im HI. Pathophysiological role of neuroinflammation in neurodegenerative diseases and psychiatric disorders. Int Neurourol J 2016;20(Suppl 1):S2-7.

26. Ben Haim L, Carrillo-de Sauvage MA, Ceyzériat K, Escartin C. Elusive roles for reactive astrocytes in neurodegenerative diseases. Front Cell Neurosci 2015;9:278.

27. Heneka MT, Kummer MP, Latz E. Innate immune activation in neurodegenerative disease. Nat Rev Immunol 2014;14:463-77.

28. Rothhammer V, Borucki DM, Tjon EC, Takenaka MC, Chao CC, Ardura-Fabregat A, et al. Microglial control of astrocytes in response to microbial metabolites. Nature 2018;557:724-8.

29. Liddelow SA, Barres BA. Reactive astrocytes: production, function, and therapeutic potential. Immunity 2017;46:957-67.

30. Liddelow SA, Guttenplan KA, Clarke LE, Bennett FC, Bohlen CJ, Schirmer L, et al. Neurotoxic reactive astrocytes are induced by activated microglia. Nature 2017;541:481-7.

31. Janelidze S, Suchankova P, Ekman A, Erhardt S, Sellgren C, Samuelsson M, et al. Low IL-8 is associated with anxiety in suicidal patients: genetic variation and decreased protein levels. Acta Psychiatr Scand 2015;131:269-78.

32. Tonelli LH, Stiller J, Rujescu D, Giegling I, Schneider B, Maurer K, et al. Elevated cytokine expression in the orbitofrontal cortex of victims of suicide. Acta Psychiatr Scand 2008;117:198-206.

33. Pandey GN, Rizavi HS, Ren X, Fareed J, Hoppensteadt DA, Roberts RC, et al. Proinflammatory cytokines in the prefrontal cortex of teenage suicide victims. J Psychiatr Res 2012;46:57-63.

34. Katayama N, Nakagawa A, Umeda S, Terasawa Y, Kurata C, Tabuchi $\mathrm{H}$, et al. Frontopolar cortex activation associated with pessimistic future-thinking in adults with major depressive disorder. Neuroimage Clin 2019;23:101877.
35. Wang SS, Kamphuis W, Huitinga I, Zhou JN, Swaab DF. Gene expression analysis in the human hypothalamus in depression by laser microdissection and real-time PCR: the presence of multiple receptor imbalances. Mol Psychiatry 2008;13:786-99.

36. Clark SM, Pocivavsek A, Nicholson JD, Notarangelo FM, Langenberg P, McMahon RP, et al. Reduced kynurenine pathway metabolism and cytokine expression in the prefrontal cortex of depressed individuals. J Psychiatry Neurosci 2016;41:386-94.

37. Schmitz ML, Shaban MS, Albert BV, Gökçen A, Kracht M. The crosstalk of endoplasmic reticulum (ER) stress pathways with NF$\kappa \mathrm{B}$ : complex mechanisms relevant for cancer, inflammation and infection. Biomedicines 2018 May 16;6(2). pii: E58. https://doi. org/10.3390/biomedicines6020058.

38. Shih RH, Wang CY, Yang CM. NF-kappaB signaling pathways in neurological inflammation: a mini review. Front Mol Neurosci 2015;8:77.

39. Hsiao HY, Chen YC, Chen HM, Tu PH, Chern Y. A critical role of astrocyte-mediated nuclear factor- $\mathrm{kB}$-dependent inflammation in Huntington's disease. Hum Mol Genet 2013;22:1826-42.

40. Xu J, Li K, Zhang L, Liu QY, Huang YK, Kang Y, et al. Dysbiosis of gut microbiota contributes to chronic stress in endometriosis patients via activating inflammatory pathway. Reprod Dev Med 2017;1:221-7.

41. Miklowitz DJ, Portnoff LC, Armstrong CC, Keenan-Miller D, Breen EC, Muscatell KA, et al. Inflammatory cytokines and nuclear factor-kappa B activation in adolescents with bipolar and major depressive disorders. Psychiatry Res 2016;241:315-22.

42. Wang Y, Xu J, Liu Y, Li Z, Li X. TLR4-NF- $\mathrm{BB}$ signal involved in depressive-like behaviors and cytokine expression of frontal cortex and hippocampus in stressed C57BL/6 and ob/ob mice. Neural Plast 2018;2018:7254016.

43. Liu L, Dong Y, Shan X, Li L, Xia B, Wang H. Anti-depressive effectiveness of baicalin in vitro and in vivo. Molecules 2019 Jan 17;24(2). pii: E326. https://doi.org/10.3390/molecules24020326.

44. Martín-Hernández D, Caso JR, Javier Meana J, Callado LF, Madrigal JLM, García-Bueno B, et al. Intracellular inflammatory and antioxidant pathways in postmortem frontal cortex of subjects with major depression: effect of antidepressants. J Neuroinflammation 2018;15:251.

45. Gárate I, García-Bueno B, Madrigal JL, Bravo L, Berrocoso E, Caso $J R$, et al. Origin and consequences of brain Toll-like receptor 4 pathway stimulation in an experimental model of depression. J Neuroinflammation 2011;8:151.

46. Lotrich F. Inflammatory cytokines, growth factors, and depression. Curr Pharm Des 2012;18:5920-35. 
47. Loftis JM, Hauser P. The phenomenology and treatment of interferon-induced depression. J Affect Disord 2004;82:175-90.

48. Dowlati Y, Herrmann N, Swardfager W, Liu H, Sham L, Reim EK, et al. A meta-analysis of cytokines in major depression. Biol Psychiatry 2010;67:446-57.

49. Miller GE, Rohleder N, Stetler C, Kirschbaum C. Clinical depression and regulation of the inflammatory response during acute stress. Psychosom Med 2005;67:679-87.

50. Pace TW, Mletzko TC, Alagbe O, Musselman DL, Nemeroff CB, Miller AH, et al. Increased stress-induced inflammatory responses in male patients with major depression and increased early life stress. Am J Psychiatry 2006;163:1630-3.

51. Barbierato M, Facci L, Argentini C, Marinelli C, Skaper SD, Giusti P. Astrocyte-microglia cooperation in the expression of a pro-inflammatory phenotype. CNS Neurol Disord Drug Targets 2013; 12:608-18.

52. Eyerich K, Dimartino V, Cavani A. IL-17 and IL-22 in immunity: driving protection and pathology. Eur J Immunol 2017;47:607-14.

53. Köhler CA, Freitas TH, Stubbs B, Maes M, Solmi M, Veronese N, et al. Peripheral alterations in cytokine and chemokine levels after antidepressant drug treatment for major depressive disorder: systematic review and meta-analysis. Mol Neurobiol 2018;55:4195206.

54. Schmidt FM, Lichtblau N, Minkwitz J, Chittka T, Thormann J, Kirkby KC, et al. Cytokine levels in depressed and non-depressed subjects, and masking effects of obesity. J Psychiatr Res 2014;55:2934.

55. Himmerich H, Fischer J, Bauer K, Kirkby KC, Sack U, Krügel U. Stress-induced cytokine changes in rats. Eur Cytokine Netw 2013;24:97-103.

56. Kinney JW, Bemiller SM, Murtishaw AS, Leisgang AM, Salazar AM, Lamb BT. Inflammation as a central mechanism in Alzheimer's disease. Alzheimers Dement (N Y) 2018;4:575-90.

57. Postal M, Lapa AT, Sinicato NA, de Oliveira Peliçari K, Peres FA, Costallat LT, et al. Depressive symptoms are associated with tumor necrosis factor alpha in systemic lupus erythematosus. J Neuroinflammation 2016;13:5. https://doi.org/10.1186/s12974-015-0471-9.

58. Köhler CA, Freitas TH, Maes M, de Andrade NQ, Liu CS, Fernandes BS, et al. Peripheral cytokine and chemokine alterations in depression: a meta-analysis of 82 studies. Acta Psychiatr Scand 2017;135:373-87.

59. Muthuramalingam A, Menon V, Rajkumar RP, Negi VS. Is depression an inflammatory disease? Findings from a cross-sectional study at a tertiary care center. Indian J Psychol Med 2016;38:114-9.

60. Hannestad J, DellaGioia N, Bloch M. The effect of antidepressant medication treatment on serum levels of inflammatory cytokines: a meta-analysis. Neuropsychopharmacology 2011;36:2452-9.

61. Liu X, Quan N. Microglia and CNS interleukin-1: beyond immunological concepts. Front Neurol 2018;9:8.

62. Gelman PL, Flores-Ramos M, López-Martínez M, Fuentes CC, Grajeda JP. Hypothalamic-pituitary-adrenal axis function during perinatal depression. Neurosci Bull 2015;31:338-50.

63. Keller J, Gomez R, Williams G, Lembke A, Lazzeroni L, Murphy GM Jr, et al. HPA axis in major depression: cortisol, clinical symptomatology and genetic variation predict cognition. Mol Psychiatry 2017;22:527-36.

64. Herman JP, McKlveen JM, Ghosal S, Kopp B, Wulsin A, Makinson $\mathrm{R}$, et al. Regulation of the hypothalamic-pituitary-adrenocortical stress response. Compr Physiol 2016;6:603-21.

65. Goshen I, Yirmiya R. Interleukin-1 (IL-1): a central regulator of stress responses. Front Neuroendocrinol 2009;30:30-45.

66. Sahay A, Hen R. Adult hippocampal neurogenesis in depression. Nat Neurosci 2007;10:1110-5.

67. Zhang B, Wang PP, Hu KL, Li LN, Yu X, Lu Y, et al. Antidepressantlike effect and mechanism of action of honokiol on the mouse lipopolysaccharide (LPS) depression model. Molecules 2019;24(11). pii: E2035. https://doi.org/10.3390/molecules24112035.

68. Black C, Miller BJ. Meta-analysis of cytokines and chemokines in suicidality: distinguishing suicidal versus nonsuicidal patients. Biol Psychiatry 2015;78:28-37.

69. Pandey GN, Rizavi HS, Zhang H, Bhaumik R, Ren X. Abnormal protein and mRNA expression of inflammatory cytokines in the prefrontal cortex of depressed individuals who died by suicide. J Psychiatry Neurosci 2018;43:170192.

70. Torres-Platas SG, Cruceanu C, Chen GG, Turecki G, Mechawar N. Evidence for increased microglial priming and macrophage recruitment in the dorsal anterior cingulate white matter of depressed suicides. Brain Behav Immun 2014;42:50-9.

71. Ovaskainen Y, Koponen H, Jokelainen J, Keinänen-Kiukaanniemi S, Kumpusalo E, Vanhala M. Depressive symptomatology is associated with decreased interleukin-1 beta and increased interleukin-1 receptor antagonist levels in males. Psychiatry Res 2009;167:73-9.

72. Borovcanin MM, Jovanovic I, Radosavljevic G, Pantic J, Minic Janicijevic S, Arsenijevic N, et al. Interleukin-6 in schizophrenia-is there a therapeutic relevance? Front Psychiatry 2017;8:221.

73. Hodes GE, Ménard C, Russo SJ. Integrating Interleukin-6 into depression diagnosis and treatment. Neurobiol Stress 2016;4:15-22.

74. Brown JA, Sherrod SD, Goodwin CR, Brewer B, Yang L, Garbett $\mathrm{KA}$, et al. Metabolic consequences of interleukin- 6 challenge in developing neurons and astroglia. J Neuroinflammation 2014;11:183. 
75. Prinz M, Priller J. Microglia and brain macrophages in the molecular age: from origin to neuropsychiatric disease. Nat Rev Neurosci 2014;15:300-12.

76. Carboni L, McCarthy DJ, Delafont B, Filosi M, Ivanchenko E, Ratti $\mathrm{E}$, et al. Biomarkers for response in major depression: comparing paroxetine and venlafaxine from two randomised placebo-controlled clinical studies. Transl Psychiatry 2019;9:182.

77. Haapakoski R, Mathieu J, Ebmeier KP, Alenius H, Kivimäki M. Cumulative meta-analysis of interleukins 6 and $1 \beta$, tumour necrosis factor $\alpha$ and $C$-reactive protein in patients with major depressive disorder. Brain Behav Immun 2015;49:206-15.

78. Chen WC, Lai HC, Su WP, Palani M, Su KP. Bupropion for interferon-alpha-induced depression in patients with hepatitis $C$ viral infection: an open-label study. Psychiatry Investig 2015;12:142-5.

79. Réus GZ, Nacif MP, Abelaira HM, Tomaz DB, dos Santos MA, Carlessi AS, et al. Ketamine ameliorates depressive-like behaviors and immune alterations in adult rats following maternal deprivation. Neurosci Lett 2015;584:83-7.

80. Ramirez K, Shea DT, McKim DB, Reader BF, Sheridan JF. Imipramine attenuates neuroinflammatory signaling and reverses stressinduced social avoidance. Brain Behav Immun 2015;46:212-20.

81. Goldsmith DR, Rapaport MH, Miller BJ. A meta-analysis of blood cytokine network alterations in psychiatric patients: comparisons between schizophrenia, bipolar disorder and depression. Mol Psychiatry 2016;21:1696-709.

82. Khandaker GM, Pearson RM, Zammit S, Lewis G, Jones PB. Asso- ciation of serum interleukin 6 and C-reactive protein in childhood with depression and psychosis in young adult life: a populationbased longitudinal study. JAMA Psychiatry 2014;71:1121-8.

83. Hodes GE, Pfau ML, Leboeuf M, Golden SA, Christoffel DJ, Bregman D, et al. Individual differences in the peripheral immune system promote resilience versus susceptibility to social stress. Proc Natl Acad Sci U S A 2014;111:16136-41.

84. Hsu B, Wang D, Sun Y, Salvadore G, Singh J, Curran M. SAT0182 improvement in measures of depressed mood and anhedonia, and fatigue, in a randomized, placebo-controlled, phase 2 study of sirukumab, a human anti-interleukin-6 antibody, in patients with rheumatoid arthritis. Ann Rheum Dis 2015;74:720-1.

85. Liu Y, Ho RC, Mak A. Interleukin (IL)-6, tumour necrosis factor alpha (TNF- $\alpha$ ) and soluble interleukin-2 receptors (sIL-2R) are elevated in patients with major depressive disorder: a meta-analysis and meta-regression. J Affect Disord 2012;139:230-9.

86. Talarowska M, Szemraj J, Gałecki P. The role of interleukin genes in the course of depression. Open Med (Wars) 2016;11:41-8.

87. Walker AJ, Foley BM, Sutor SL, McGillivray JA, Frye MA, Tye SJ. Peripheral proinflammatory markers associated with ketamine response in a preclinical model of antidepressant-resistance. Behav Brain Res 2015;293:198-202.

88. Yang SK. Psycho-urology: possible links between stress, anxiety, depression and bladder function. J Korean Continence Soc 2006; $10: 1-8$. 